\title{
Formação em pesquisa na pós-graduação: práticas e desafios. A formação do pesquisador em Educação na Universidade do Estado da Bahia
}

\section{Postgraduate Research Training: practices and challenges. The formation of the researcher in Education at the State University of Bahia}

\author{
Antônio Dias Nascimento*
}

\begin{abstract}
RESUMO
Este artigo analisa a formação do pesquisador no Programa de Pós-Graduação em Educação e Contemporaneidade, PPGEduC, da Universidade do Estado da Bahia (UNEB) constituído à luz da experiência histórica de outras universidades e das normas que regem a pós-graduação no Brasil cujo mestrado foi recomendado pela Coordenação de Aperfeiçoamento de Pessoal de Nível Superior (CAPES) em 1999 e o doutorado em 2008. A metodologia utilizada constituiu-se de consultas bibliográficas e documentais. Os estudos desenvolvidos no programa giram em torno da educação no contexto da crise da modernidade a partir de quatro linhas de pesquisa a saber Processos Civilizatórios: Educação, Memória e Pluralidade Cultural; Educação, Práxis Pedagógica e Formação do Educador; Educação, Gestão e Desenvolvimento Local Sustentável; e Educação, Currículo e Processos Tecnológicos. Essas linhas são integradas por 23 grupos de pesquisa certificados pelo Conselho Nacional de Desenvolvimento Científico e Tecnológico (CNPq). No que pese a diversidade de perspectivas analíticas assumidas pelos diversos membros do Programa, todos reconhecem a crise da modernidade e convergem entre si no propósito de buscar novas utopias considerando a centralidade da pessoa humana, a defesa do meio ambiente e o uso humanitário das tecnologias

* Universidade do Estado da Bahia. Programa de Pós-Graduação em Educação e Contemporaneidade. Salvador, Bahia, Brasil. E-mail: andiasst@hotmail.com. https://orcid.org/0000-
\end{abstract} 0002-8665-8609. 
da informação e da comunicação. Diante do cenário de incertezas e perplexidades, os estudos desenvolvidos no programa visam à produção de um conhecimento que favoreça a produção e reprodução da dignidade humana. Finalmente, são apresentadas algumas considerações gerais, destacando alguns aspectos importantes que caracterizam o Programa e o processo de formação dos pesquisadores.

Palavras-chave: Formação do Pesquisador na Pós-Graduação. Pesquisa em Educação. Pesquisa em Educação e Contemporaneidade.

\begin{abstract}
This paper presents an analysis of the researcher's training in the PostGraduate Program in Education and Contemporaneity, PPGEduC, of the State University of Bahia, UNEB, constituted in the light of the historical experience of other universities and the norms that govern post-graduation in Brazil, whose master's degree course was recommended by CAPES in 1999 and its doctorate in 2008. The methodology used consisted of bibliographical and documentary consultations. The studies developed in the program revolve around education in the context of the crisis of modernity from four lines of research namely Civilizational Processes: Education, Memory and Cultural Plurality; Education, Pedagogical Praxis and Educator Training; Education, Management and Sustainable Local Development; and Education, Curriculum and Technological Processes. These lines are composed of 23 research groups certified by CNPq. In spite of the diversity of analytical perspectives assumed by the various members of the Program, all recognize the crisis of modernity and converge with one another in the purpose of seeking new utopias considering the centrality of the human person, the defense of the environment and the humanitarian use of information technologies and communication. Given the scenario of uncertainties and perplexities, the studies developed in the program aim at producing knowledge that favors the production and reproduction of human dignity. Finally, some general considerations are presented, highlighting some important aspects that characterize the Program and the process of training the researchers.
\end{abstract}

Keywords: Researcher Training in Post-Graduation. Research in Education. Research in Education and Contemporaneity. 


\section{Introdução}

No presente trabalho há uma análise sobre o desenvolvimento da formação em pesquisa na pós-graduação em educação da Universidade do Estado da Bahia (UNEB). Seguindo a trajetória das universidades brasileiras, emergidas timidamente a partir dos anos de 1920, constituindo-se da junção de vários cursos preexistentes e voltadas para a formação de profissionais liberais, sem ênfase na pesquisa como nos lembra Gatti (2001), também a UNEB surgiu, em 1983, a partir da união de vários cursos superiores mantidos pelo governo estadual, visando ao aperfeiçoamento dos docentes do ensino básico do Estado da Bahia. Atualmente, embora predominem as licenciaturas nos seus diversos campi, já foram criados vários cursos em outras áreas de conhecimento. A formação em pesquisa, no entanto, por meio de curso stricto sensu, somente teve início no ano 2000, com a instituição do Programa de Pós-graduação em Educação e Contemporaneidade, ou seja, 17 anos depois de sua fundação como Universidade e 45 anos após a instituição do ensino de pós-graduação no Brasil, por intermédio do histórico Parecer 977/65, cujo relator foi o professor Newton Sucupira.

A preocupação em formar quadros de alto nível, como uma das estratégias básicas para o desenvolvimento do país, ganha maior intensidade com a desmobilização da Segunda Guerra Mundial, quando a produção do conhecimento passa a ser realçada como condição necessária para a conquista da autonomia nacional no conjunto das nações (GOUVÊA, 2012). Dada a posição geopolítica do Brasil na América Latina e ao seu grande potencial energético e de grandes reservas de minerais estratégicos, criou-se no seio da intelligentsia brasileira a consciência de que, para ultrapassarmos a extrema dependência das commodities, era necessário formar quadros de alto nível para produzirmos internamente o conhecimento necessário para a apropriação e o desenvolvimento de nossos recursos naturais, uma vez que as nações mais desenvolvidas, além de não transferirem know-how o detinham como reserva de valor e de mercado transformando-o em um mecanismo a mais de dominação e de exercício de poder sobre as demais nações.

Assim, no ano de 1951, como resultado das grandes mobilizações realizadas pela Sociedade Brasileira para o Progresso da Ciência, desde a sua fundação em 1948, foram criadas as duas grandes agências nacionais de fomento à formação de quadros de alto nível, tanto para o desenvolvimento da pesquisa, quanto para o aprimoramento do ensino superior. Em janeiro de 1951, foi criado o Conselho Nacional de Pesquisa, CNPq, através da Lei 1.310 de 15 janeiro de 1951, saudada pelo Almirante Álvaro Alberto da Motta e Silva, como a Lei 
Áurea da Pesquisa no Brasil (CNPq, 2018). Seis meses após a criação do CNPq, foi criada a Coordenação Nacional de Aperfeiçoamento de Pessoal de Nível Superior (atual Capes), através do Decreto 29.741, de 11 de julho de 1951, com o objetivo de cuidar do aprimoramento do ensino superior. Sua gestão ficou a cargo do Professor Anísio Spínola Teixeira até a implantação dos governos militares.

Em razão da importância estratégica para o desenvolvimento nacional, as duas agências estiveram ligadas diretamente à Presidência da República até o colapso do populismo em março de1964. Mais tarde, o CNPq é transferido para a jurisdição do Ministério da Ciência e Tecnologia e a CAPES, para a jurisdição do Ministério da Educação. Por sua vez, a Coordenação Nacional de Aperfeiçoamento de Pessoal de Nível Superior assumiu tanto o encargo de analisar e recomendar, os cursos de pós-graduação de todas as universidades brasileiras, assim como avaliá-los periodicamente quanto ao progresso, estagnação, ou regresso do seu desempenho.

A partir dos Planos Nacionais de Desenvolvimento, que tiveram início no final da década de 1960, houve uma grande mobilização em todas a Regiões do País, a cargo do Governo Federal, expressa por meio da construção de grandes obras como barragens, tais como a Binacional Itaipu, 11 barragens ao longo do curso do Rio São Francisco para a produção de energia e controle do curso, rodovias de longa distância como a Transamazônica, a Perimetral Norte, Cuiabá-Santarém e outras. Todos esses investimentos acarretaram também deslocamentos populacionais tanto de áreas rurais para outras áreas rurais, como de áreas rurais para áreas urbanas, ou mesmo de áreas urbanas para outras áreas urbanas.

Todos esses fatos fizeram crescer ainda mais a demanda por pesquisadores e quadros especializados em todas as áreas de conhecimento para estudos e análises dos efeitos dessas mudanças sobre a cena brasileira. Nesse bojo de mudanças aumentaram, também, consideravelmente, os esforços dos governos estaduais em prol do desenvolvimento em âmbito regional. Entre as várias medidas encaminhadas para enfrentar as exigências do progresso, foram criadas agências estaduais de apoio à pesquisa com dotações orçamentárias previstas nas respectivas constituições estaduais, as universidades públicas já existentes intensificaram os esforços para a criação de sua pós-graduação e o fomento à pesquisa, tendo sido criadas universidades estaduais e entre elas a Universidade do Estado da Bahia - UNEB. Mais recentemente, a partir dos anos 2000, foram estabelecidas novas universidades federais com corpos docentes bem qualificados que possibilitaram a instalação da pós-graduação stricto sensu já nos seus primeiros anos de existência.

Via de regra, os setores encarregados da pesquisa, ligados à administração direta das universidades, voltam-se para a administração dos programas já instituídos como bolsas de estudo para a realização de pós-graduação, programa de 
iniciação científica, divulgação de chamadas públicas das agências de fomento à pesquisa tais como CNPq, CAPES, Finep e Fundações estaduais de apoio à pesquisa e ao desenvolvimento científico, lançamento de editais para apresentação de projetos de pesquisa e atribuição de prêmios. Desse modo, essas estruturas de fomento à pesquisa, internas às universidades, funcionam como mediadoras entre as Agências e os pesquisadores. Embora as Universidades tenham fundações de apoio à pesquisa e extensão, em boa medida, prevalecem as ações de extensão. Os projetos de pesquisa demandados à universidade, por instituições públicas ou privadas, obedecem a critérios diferentes dos programas regulares de apoio à pesquisa. Em geral esses projetos são abrigados pelas fundações e, comumente, são liderados por professores pesquisadores que se destacam em suas áreas de conhecimento e alcançam notoriedade mesmo fora do âmbito das universidades e, por isso mesmo, frequentemente, são convidados pelas instituições demandantes. Nesses casos, as fundações ligadas às universidades prestam o necessário apoio administrativo ao desenvolvimento da pesquisa.

\section{A instauração da pós-graduação em Educação na Bahia}

O primeiro curso de pós-graduação em Educação na Bahia, no entanto, surge em 1971, na Universidade Federal da Bahia, UFBA, mesmo assim, com apenas um curso de mestrado, permanecendo nessa condição até 1995, quando teve o seu curso de doutorado recomendado pela CAPES, ou seja, decorridos 30 anos após o histórico parecer de Sucupira. Enquanto isso, nas Regiões Sul e Sudeste esses cursos já vicejavam desde a década de 1960. Esses programas, por sua vez, atendiam mestrandos e doutorandos, tanto dessas regiões pioneiras, como das demais regiões do Brasil que, por sua vez, se mantinham com os seus cursos de graduação e alguns cursos de pós-graduação lato sensu. Nem sempre os alunos provindos de outras regiões do País contavam com o necessário suporte financeiro para arcar com os custos de deslocamento e instalação nos respectivos lugares onde deveriam frequentar os cursos para os quais eventualmente eram selecionados.

Assim, grande parte dos primeiros doutores em Educação, não somente da Bahia, como do restante dos demais estados das Regiões Nordeste, Norte e Centro-Oeste fizeram suas respectivas formações doutorais nos Programas de Pós-graduação das Regiões Sul e Sudeste ou no exterior, com predominância da França, Espanha, Reino Unido, Estados Unidos, México e Argentina (RAMALHO; MADEIRA, 2005). Ao retornarem às suas respectivas regiões 
de origem, muitos desses doutores foram constituindo grupos de estudos e de pesquisa em torno de seus interesses acadêmicos e das respectivas realidades regionais. Desse modo, foi-se constituindo uma massa crítica que, inicialmente, realizou tirocínios preparatórios para voos mais altos em cursos stricto sensu, realizando cursos de especialização, de aperfeiçoamento e de extensão, ou seja, lato sensu, com duração mínima de 360 horas e, quase sempre, com a produção de uma monografia.

No caso da UNEB, depois de um considerável período oferecendo cursos lato sensu, fortaleceram-se três importantes grupos de estudos e pesquisas e cada um com pretensões a tornar-se um programa stricto sensu à parte. Um deles voltado para a memória da educação e formação de professores; um outro, para a educação, gestão, desenvolvimento local e sustentabilidade e, o terceiro, mais voltado para a Educação e às tecnologias da informação e comunicação. Após a submissão das propostas à CAPES, a comissão de especialistas que as analisou sugeriu que as três tendências fossem integradas em um único programa, cuja orientação básica seria o binômio Educação e Contemporaneidade, mesmo porque já havia um outro programa de pós-graduação stricto sensu na área da educação no Estado da Bahia. As três tendências iniciais em torno das quais se agrupavam os pesquisadores foram transformadas em linhas de pesquisa do Programa de Pós-graduação em Educação e Contemporaneidade. Contando com a anuência dos professores pesquisadores da UNEB, oriundos dos três grupos de pesquisa, o curso de mestrado em Educação e Contemporaneidade foi recomendado pela CAPES, no final de 1999 e realizou sua primeira seleção no início do ano 2000. Até o ano de 2017, foram graduados 506 mestres e 84 doutores entre 2008 e 2017.

Evidentemente que a junção dessas três tendências iniciais em um único programa de pós-graduação, no que pese haver tornado possível o início de cursos stricto sensu na Universidade do Estado da Bahia, constituiu um campo científico marcado pela diversidade de visões e leituras de mundo que, em vez de inviabilizar o Programa, o tornou rico em leituras, debates, e discussões a cerca das diferentes perspectivas em torno da ideia de contemporaneidade e de como construí-la em seus respectivos interesses acadêmicos (BOURDIEU, 2004). Atualmente, o PPGEduC está constituído por quatro linhas de pesquisa, a saber: Processos Civilizatórios - Educação, Memória e Pluralidade Cultural; Educação, Práxis Pedagógica e Formação do Educador; Educação, Gestão e Desenvolvimento Local Sustentável; e Educação, Currículo e Processos Tecnológicos. Talvez um dos fatores que asseguraram a unidade nessa diversidade foi o reconhecimento por todos os professores pesquisadores da crise do projeto moderno de civilização, como descrito por Lyotard (2004) e a busca por novas utopias, ou seja, a constituição de um "capital científico". Segundo Ragouet (2017), 
Na sociologia de Bourdieu, qualquer campo social é um espaço de concorrência estruturada em torno de desafios e de interesses específicos no âmago do qual os "agentes" se distribuem em função do volume e da estrutura de capitais detidos por eles e que constituem os recursos da ação. A forma de interesse específico no campo científico consiste na imposição de uma concepção particular de ciência graças à mobilização de recursos aos quais Bourdieu atribui a denominação de "capital científico". (RAGOEUT, 2017, p. 68-69).

O embate intelectual entre as três linhas do PPGEduC tem assegurado o seu desenvolvimento, respeitando-se as alteridades, em vez de se assimilarem umas às outras, ou de aprofundarem as suas divergências. Anos mais tarde, foi criada mais uma linha de pesquisa - Educação, currículo e Processos Tecnológicos. Outro fator que fortalece essa unidade na diversidade é a abertura de espaços, dentro de cada linha em particular, representados pelos 23 grupos de pesquisa, todos eles certificados pelo CNPq. Em consonância com os demais programas de pós-graduação do Brasil, os grupos de pesquisa se constituem em bases fundamentais de pesquisa e de formação de pesquisadores. Recorrendo mais uma vez a Gatti (2005), a autora atribui aos grupos de pesquisa, entre outros ambientes sociais de troca e produção de conhecimento, "um poder formativo inestimável".

Como acontece em boa parte das universidades brasileiras, os cursos de pós-graduação são mais voltados para o aperfeiçoamento de professores do ensino superior, no entanto, dado ao caráter stricto sensu desses cursos, tem sido neles que se tem sido realizada a formação dos pesquisadores. A junção desses dois propósitos, o aperfeiçoamento de professores para o ensino superior e a formação de pesquisadores, no desenvolvimento dos cursos de pós-graduação, nem sempre foi aceita sem restrições por estudiosos da questão, como se pode perceber nas palavras de Gatti, em 2001. Segundo a autora,

A integração da pesquisa como parte da vida universitária, como processo induzido, via mestrados e doutorados, acaba por criar uma vinculação excessiva entre a pesquisa e a pós-graduação na maioria das instituições, quando o desejável seria um espalhamento das atividades de investigação científica dentro de toda a vida acadêmica. O que se assistiu na maioria das instituições foi a concentração das atividades de pesquisa na pós-graduação, sendo aí o único espaço em que alguma pesquisa veio a ser realizada. Várias universidades, especialmente públicas e algumas comunitárias, caminharam lentamente para o desenvolvimento de grupos 
científicos que se interligam com os cursos de mestrado e doutorado, mas que adquiriram vida própria e têm um espaço institucional específico conectando-se com diferentes atividades acadêmicas. Porém, a grande maioria das instituições, especialmente as privadas, não integraram a pesquisa em seu cotidiano, trabalhando praticamente só com professores horistas. Também não se empenharam quanto ao aperfeiçoamento dos seus quadros, a não ser mais recentemente, por pressão de normatizações legais. (GATTI, 2001, p. 110).

Seguindo a tendência da maioria das universidades brasileiras, no âmbito da UNEB, a pesquisa também permaneceu associada no ensino de pós-graduação visando ao aperfeiçoamento de pessoal docente para o ensino superior. Com essa advertência de Gatti, no entanto, procurou-se no PPGEduC, intensificar as atividades de formação do pesquisador, instituindo um conjunto de atividades que envolvem ao mesmo tempo o desenvolvimento de uma base teórico-metodológica, exercícios de investigação científica, a escrita e o debate acadêmicos, como será visto adiante.

\section{Sobre a organização dos cursos}

Como já mencionado acima, o pensamento dominante que serviu de amálgama às três linhas de pesquisa foi a reflexão sobre a crise da modernidade, tendo como ponto central as suas limitações como projeto civilizatório, sendo essas limitações expressas de várias maneiras. Entre os diferentes elementos de mal-estar, causados pela modernidade, destaca-se a predominância da racionalidade acadêmica, apontada por diversos pensadores, como eixo básico do etnocentrismo e uma das suas principais limitações é a exclusão de outras formas de saber. Na contramão da primazia atribuída ao saber acadêmico, surge a afirmação de outros saberes. Não significando isso a negação do saber acadêmico, mas a sua relativização, passando ele a ser considerado como um saber entre outros, produzidos em outros espaços sociais (LYOTARD, 2004). Uma outra característica da nova era, não obstante todas as sombras que tornam incerto o futuro da humanidade, é a emergência da valorização da vida, a convivência com os diferentes, a ideia de ética como o respeito e o cuidado pela alteridade, assim como a retomada da consciência moral das pessoas e não dos ditames heterônomos impostos pela sociedade de classes (BAUMAN, 2003). 
A ideia de contemporaneidade, no que pese a polissemia do termo, é assumida como a possibilidade de emergência de novas utopias e não apenas como o fim da modernidade, como sugerem certas expressões que se assumem como pós-modernas. Assim, importa não a superação das incertezas, tampouco a perpetuação dos determinismos impostos pelos diversos processos civilizatórios, mas como diz Martins (2012, p. 9) , a descoberta

do homem simples e cotidiano, cuja existência é atravessada por mecanismos de dominação e de alienação que distorcem sua compreensão da História e do próprio sentido. Todos nós somos esse homem que não só luta para viver a vida de todo dia, mas que luta também para compreender um viver que lhe escapa porque não raro se apresenta como absurdo, como se fosse um viver destituído de sentido.

Essa busca deve ser realizada com base em perspectivas metodológicas que permeiam todo o universo das ciências humanas para que, continuando ainda com Martins (2012, p. 9),

o homem comum se torne agente ativo de seu destino, neste tempo da modernidade, numa sociedade de modernidade frágil como a nossa sociedade brasileira. Uma sociedade dividida de muitos modos, marcada pela diversidade de tempos que se adiantam e que se atrasam, negando-se, por isso na falta da coerência, ainda que aparente, que é tão característica das sociedades propriamente modernas.

Por sua vez, a ideia de educação assumida é a de que ela se dá em um processo coletivo, tendo como sujeito o próprio educando na sua relação com os outros, apoiado em constante reflexão sobre a realidade em que se está inserido e na ética de valorização da vida. Assim a educação exclui toda e qualquer relação de heteronomia e submissão, busca a emancipação dos sujeitos e a sua sobrevivência é assegurada pelo diálogo com os demais e pela sua participação em todas as instâncias de decisão da vida em comum (ADORNO, 1995). Nesse sentido, a educação difere da escolarização. A educação supõe a emancipação de si e dos outros, enquanto a escolarização é um percurso disciplinar que supõe a transmissão de conhecimento onde os que sabem, ensinam e os que não sabem, aprendem. A escolarização, pura e simplesmente, desprovida da humanização, exime a participação dos aprendentes na condução do nosso destino comum. 
Não se nega o valor da escola como uma agência de formação, todavia a sua ação se dá em meio a uma ferrenha disputa de espaço com outras agências formadoras, como a mídia por exemplo. A escola, em si mesma, não é boa, nem é má, depende de quem esteja lá”, como se expressam Flecha e Tortajada (2000).

Por fim, impõe-se nesse nível de estudo o despertar para a pesquisa, como sendo a busca do desconhecido para ampliar o conhecimento de si, dos outros e do mundo. Portanto, ela não tem uma finalidade em si mesma. A sua importância está diretamente relacionada à construção de um saber que favoreça à vida por meio de processos de emancipação dos indivíduos. Assim, a pesquisa não é indiferente às condições ambientais em que ela acontece, nem aos sujeitos que a conduzem, nem aos quais os seus resultados se destinam. Daí a necessidade de que, por meio dela, se possa produzir um conhecimento que seja útil à produção e à reprodução da vida. Assume-se que no processo de investigação social, os seres humanos são sempre os sujeitos da produção do conhecimento e a eles devem ser devolvidos, para seu proveito, todos os achados. Até o presente, nas pesquisas realizadas tanto para a elaboração das teses, como dissertações, há uma predominância dos arranjos metodológicos qualitativos. Esses arranjos variam entre histórias de vida, abordagens etnográficas, autobiografia, história oral sobretudo quando se trabalha com sujeitos ágrafos, estudos de caso com base em entrevistas abertas, observações participantes entre outros.

A preparação para a pesquisa, portanto, nos cursos de mestrado e doutorado do Programa de Pós-graduação em Educação e Contemporaneidade, PPGEduC, têm início em uma leitura crítica do mundo, pautada em trabalhos de pensadores que contribuem para o entendimento da crise da modernidade e a emergência de novos paradigmas que possam servir de base para a construção de novas utopias caracterizadas pelo respeito à dignidade humana e à alteridade. Ou seja, parte-se de uma aproximação preliminar do contexto do objeto que se pretende estudar, com base em estudos exploratórios, e, posteriormente, com o suporte de uma banca examinadora no exame de qualificação se define um projeto de pesquisa que se conclui com a elaboração de uma tese ou de uma dissertação, conforme o caso.

Parte-se, mediante a pesquisa, em busca de uma compreensão tão profunda quanto possível, do objeto em seu conjunto de relações que o constituem e o envolvem. Essa compreensão, em razão da especificidade dinâmica da realidade, não assume caráter definitivo, pois ela é, a um só tempo, ponto de chegada ao final do curso - doutorado ou mestrado - e de partida para novas investigações. A leitura de mundo, referida acima, torna-se fundamental para que se possa perceber o dinamismo e o conjunto das relações que envolvem o objeto estudado. No caso do PPGEduC, em vista de sua preocupação central com os desconfortos da modernidade sobre os sujeitos, o foco principal de orientação da pesquisa circunscreve-se em torno do binômio educação versus emancipação. 
Para o desenvolvimento dessas reflexões foram criadas três disciplinas obrigatórias, no curso de mestrado, para os alunos de todas as linhas que são admitidos a cada ano, tais como: Bases Filosóficas da Contemporaneidade, Educação e Contemporaneidade e Pesquisa em Educação. Complementarmente são oferecidas três disciplinas obrigatórias, uma por cada linha de pesquisa, abordando os temas próprios dos interesses teóricos da linha. Além dessas, são oferecidas disciplinas opcionais a cargo dos professores pesquisadores que ampliam o espectro, tanto das reflexões desenvolvidas nas disciplinas obrigatórias para todos, como nos exercícios de leitura de mundo em função das preocupações teóricas de cada líder de grupo de pesquisa. No caso do doutorado, com duração prevista de quatro anos, as disciplinas são apenas três: Estudos Avançados em Educação e Contemporaneidade, Seminário de Formação Teórico-Metodológica I e Seminário de Formação Teórico-Metodológica II. Além disso, são desenvolvidas atividades obrigatórias tais como pesquisa orientada, fórum de pesquisa em educação, estudo individual orientado, participação no seminário Educação e Contemporaneidade, frequência a alguma disciplina optativa de livre escolha, produção científica expressa através da participação em evento e publicações. Conclui-se o curso com a defesa da tese.

\section{Outras práticas formativas em pesquisa}

Enquanto são desenvolvidas as disciplinas, são realizadas outras atividades com o intuito de reforçar a formação dos pesquisadores e ao mesmo tempo assegurar o andamento coletivo das pesquisas individuais. A pesquisa exige compromisso e previsibilidade e troca de saberes. Nesse sentido, cada pós-graduando torna-se membro nato do grupo de pesquisa liderado pelo seu respectivo orientador. Além das reuniões periódicas do grupo onde se discute textos geralmente indicados pelos respectivos orientadores, ou pelos membros do grupo, esses textos podem versar sobre questões metodológicas de investigação, ou de aprofundamento de temas que caracterizam o arcabouço teórico do grupo de pesquisa. Além da participação nessas reuniões do grupo, acontecem as sessões de orientação individual entre cada pós-graduando e seu orientador, cuja periodicidade varia de acordo com o arranjo estabelecido entre os orientadores e seus orientandos.

No sentido de assegurar o andamento coletivo das pesquisas individuais, realiza-se o fórum mensal ou semestral de pesquisa de cada linha cuja participação é obrigatória. Nessa ocasião, cada grupo de pesquisa que integra a linha submete aos demais uma visão geral sobre as realizações do grupo, podendo 
responder a indagações, comentários e receber sugestões. É comum, nessas ocasiões, contar-se com a presença e participação de pesquisadores convidados de outras universidades que se destacam tanto pelo seu desempenho acadêmico, como pelas suas reflexões teóricas. Os textos apresentados por ocasião desses fóruns comumente são disponibilizados ao público pela organização e pela publicação de coletâneas. A preparação e a realização desses fóruns de pesquisa comumente são marcadas por muita tensão, em virtude do desafio dirigido a cada pós-graduando em particular, uma vez que tem de apresentar o andamento de sua pesquisa e enfrentar o debate com o conjunto dos demais membros da linha de pesquisa. A preparação de cada um para o Fórum é também uma oportunidade de reflexão e treinamento da escrita autoral dos pós-graduandos, assim como para a elaboração de suas respectivas dissertações ou teses.

Ao longo do calendário anual, acontecem eventos acadêmicos nas várias universidades brasileiras que fazem chamadas gerais para apresentação de papers, em seminários, simpósios e encontros para o estudo de temáticas específicas. Essas convocações também se constituem em ocasiões importantes de aperfeiçoamento dos pós-graduandos, assim como dos professores orientadores, pois os seus trabalhos, uma vez submetidos, são apreciados por um comitê científico que, mediante parecer escrito, pode recomendar a aceitação, a recusa ou a revisão dos trabalhos apresentados. Sendo aprovados, os trabalhos são expostos oralmente pelos respectivos autores e submetidos ao debate com seus pares da comunidade acadêmica, em sessões de apresentação oral coordenadas por professores doutores, nas quais recebem comentários críticos dos debatedores. Esses eventos também contam com a apresentação de mesas redondas em torno de questões importantes constituídas por pesquisadores de várias universidades ou centros de pesquisa. É comum ainda que desses eventos surjam novas coletâneas com trabalhos escolhidos para permitir o acesso a eles por um público mais amplo. Esses eventos são também ocasiões para articulação de redes temáticas em torno de questões específicas.

Uma outra oportunidade singular de reflexão e aprofundamento se dá por ocasião do exame de qualificação já referido anteriormente. Esse exame marca a transição de uma fase de estudos exploratórios na qual os pós-graduandos cumprem as disciplinas e se exercitam no delineamento de seus objetos específicos e no levantamento de alternativas metodológicas para o desenvolvimento da pesquisa que servirá de base para suas teses ou dissertações. Nesse rito de passagem, os pós-graduandos devem submeter a uma banca examinadora um texto previamente elaborado e sobre o qual os membros da banca tecem comentários críticos que servem à elaboração do projeto definitivo da pesquisa. Ao final desse exame, a banca examinadora elabora um parecer contendo recomendações que visam ao aperfeiçoamento do projeto de pesquisa, recomendações de leituras e outros 
procedimentos que lhes pareçam adequados para a condução da investigação e elaboração das teses ou dissertações. Como as conclusões do texto examinado são provisórias, comumente o exame é realizado sem a presença de público.

Após o exame de qualificação, inicia-se a segunda fase com o desenvolvimento da pesquisa e com a elaboração da tese ou da dissertação. Em um primeiro momento, os pós-graduandos retomam as observações e recomendações da banca examinadora e fazem ajustes finais nos seus respectivos projetos de pesquisa. Daí por diante, com maior clareza sobre os seus respectivos objetos de estudo, os arranjos metodológicos vão-se tornando cada vez mais delineados e as pesquisas vão-se encaminhando para um produto final - a tese ou a dissertação, como referido anteriormente.

Uma vez concluídas a tese ou a dissertação, elas são submetidas a uma banca examinadora. No caso do doutorado, a banca é composta de cinco membros doutores, sendo dois deles convidados externos ao PPGEduC e os dois outros, internos. O quinto integrante é o próprio orientador do pós-graduando, que preside a sessão de defesa pública. Após uma apresentação oral da tese, cada um dos membros da banca tece os seus comentários sobre o texto escrito ao qual tiveram acesso com um mês de antecedência e sobre a defesa oral e faz uma arguição ao doutorando. A critério da banca, o examinando poderá responder individualmente a cada examinador, ou, de outro modo, poderá responder a todos ao final das arguições. Após as respostas do examinando, o presidente da banca consulta aos examinadores se estão satisfeitos com as respostas ou se desejam mais aprofundamento do pós-graduando. Concluídas as arguições, a banca examinadora reúne-se em sessão privada para discutir sobre a aprovação ou não da tese, ou então, poderá conceder-se mais algum prazo para a reapresentação do trabalho. Esta última hipótese é menos provável, mesmo porque os orientadores, em geral, somente concordam com a submissão da tese, ou dissertação, quando a seu critério, ela atinge certo grau de excelência.

Para os pós-graduandos que não têm experiência em docência exige-se que eles realizem um estágio de magistério sob a supervisão de um professor de ensino superior durante um semestre, em geral dentro da própria universidade. Por sua vez, os pós-graduandos que já são docentes ficam dispensados desse estágio.

\section{Considerações finais}

O Programa de Pós-graduação em Educação e Contemporaneidade surgiu em decorrência da necessidade de ampliar, no Estado da Bahia, as oportunida- 
des de formação de quadros de alto nível na área da Educação, visando tanto ao aperfeiçoamento do seu próprio corpo docente distribuído por 29 campi, situados em praticamente todas as regiões do Estado, assim como dos corpos docentes das universidades confessionais e privadas e mesmo do ensino médio público e privado. Assim, evidencia-se o estabelecimento de uma relação entre o desenvolvimento local e o surgimento da pós-graduação.

A formação do pesquisador no PPGEduC se faz mediante intenso esforço e desenvolvimento de exercícios acadêmicos caracterizados, pela assídua frequência às disciplinas propostas, sendo todas ministradas em caráter participativo, pela leitura das referências bibliográficas elencadas em cada disciplina, pela participação em grupos de pesquisa, pela submissão de trabalhos e participação em eventos especializados nas diversas temáticas ligadas ao campo da educação, pelas discussões entre pares e mesmo com especialistas. Enfim, a formação do pesquisador se dá pelo seu envolvimento em um dinamismo de reflexão, investigação e produção de conhecimento. Dado ao movimento contínuo do real, a formação do pesquisador é sempre inconclusa e assim ela se torna tanto mais consistente quanto maior e persistente for o seu envolvimento com o processo de investigação, depois de concluídos os respectivos cursos.

\section{REFERÊNCIAS}

ADORNO, T. W. Educação e Emancipação. Rio de Janeiro: Paz e Terra, 1995.

BAUMAN, Z. Ética Pós-Moderna. São Paulo: Paulus, 2003.

Conselho Nacional de Desenvolvimento Científico e Tecnológico. Disponível em: $<$ http:// cnpq.br/a-criacao>. Acesso em: 21 fev. 2018.

FLECHA, R.; TORTAJADA, I. Desafios e saídas educativas na entrada do século. In: IMBERNÓN, F. (Org.). A educação no século XXI: os desafios do futuro imediato. Porto Alegre: Artmed, 2000. p. 21-36.

GATTI, B. A. Reflexão sobre os desafios da pós-graduação: novas perspectivas sociais, conhecimento e poder. Revista Brasileira de Educação [online], n. 18, p.108-116, 2001. Disponível em: <www.scielo.br/pdf/rbedu/n18/n18a10.pdf>. Acesso em: 9 dez. 2017.

GATTI, B. A. Formação de grupos e redes de intercâmbio em pesquisa educacional: dialogia e qualidade. Revista Brasileira de Educação, n. 30, p. 124-132. 2005, Disponível em: <http://www.scielo.br/pdf/rbedu/n30/a10n30>. Acesso em: 26 fev. 2018.

GOUVÊA, F. C. F. A institucionalização da pós-graduação no Brasil: o primeiro decênio da Capes (1951-1961). RBPG - Revista Brasileira de Pós-Graduação, Brasília, v. 9, 
n. 17, p. 373-397, jul. 2012. Disponível em: <ojs.rbpg.capes.gov.br/index.php/rbpg/ article/viewFile/312/294>. Acesso em: 9 jan. 2018.

LYOTARD, J. F. A condição pós-moderna. Rio de Janeiro: José Olympio, 2004.

MARTINS, J. S. A sociabilidade do homem simples. São Paulo: Contexto, 2012.

RAGOUET, P. Campo científico. In: CATANI, A. M. et al. Vocabulário Bourdieu. Belo Horizonte: Autêntica, 2017. p. 68-70.

RAMALHO, B. L.; MADEIRA, V. P. C. A pós-graduação em educação no Norte e Nordeste: desafios, avanços e perspectivas. Revista Brasileira de Educação, n. 30, p. 7081, número especial, set./dez. 2005. Disponível em: <www.comperve.ufrn.br/conteudo/ observatorio/.../pos-graduacao-norte-nordeste.pdf>. Acesso em: 16 nov. 2017.

Texto recebido em 17 de maio de 2018 . Texto aprovado em 17 de julho de 2018 . 